\title{
ОПРЕДЕЛЕНИЕ СОСТАВА ТЕЛА КАК ПОКАЗАТЕЛЯ ЗДОРОВЬЯ ЧЕЛОВЕКА
}

\author{
Агаджанян М.Г., Чшмаритян М.В., Саркисян М.Р. (Армянский \\ государственный институт физической культуры и спорта) \\ amg_3746@yahoo.com, tshmarit@yahoo.com, marsar2015@mail.ru

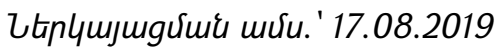 \\ qршиипикши шर्षu.' 19.08.2019

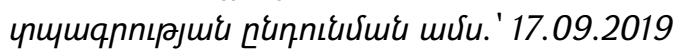

\begin{abstract}
Учение о составе тела стало актуальным направлением в области биологии, медицины и валеологии во второй половине 20-го века. Наиболее распространённым в настоящее время методом определения является биоимпедансный анализ. Измерение веса само по себе не даёт точной картины состояния организма, поскольку масса тела человека это сумма веса костей, мышц, жировой ткани, ликвора и т.д. При этом два человека с одинаковыми показателями веса и роста могут отличаться по уровню содержания жировой ткани, мышечной массы, что существенно отражается на здоровье и работоспособности. Количественная характеристика состава тела, оценка соотношения всех составляющих компонентов являются отражением баланса энергии, коррелирует с физической работоспособностью человека и отражает его адаптацию в изменяющихся условиях среды жизнедеятельности. Наиболее актуальна проблема изучения состава тела в спортивной деятельности, экстремальных условиях, морбидных и преморбидных состояниях.
\end{abstract}

Ключевые слова: состав тела, тип телосложения, оптимальный вес, антропометрические показатели, физическая работоспособность.

Вес человека индивидуален, хотя даже у одного и того же человека вес тела колеблется в довольно широких пределах (в среднем увеличение или уменьшение за сутки - от \pm 1 до $\pm 2-3$ кг, за сезон - до \pm 6-7 кг). Для получения наиболее точных данных необходимо взвешиваться утром натощак. Наиболее устойчивый период поддержания веса считается возраст от 25 до 45 лет. В пожилом и старческом возрасте наблюдается снижение веса в среднем на 10-15кг, что в основном связано с обезвоживанием организма. У детей скорость роста является абсолютным показателем положительного энергетического баланса. У взрослых изменения массы тела также свидетельствуют об изменении баланса потребляемой и затрачиваемой энергии. Вес тела зависит от типа телосложения (конституции) по теории М.В.Черноруцкого [1].

У астеничных людей тонкие кости скелета и хрупкое телосложение, они обычно высокого роста, обхват запястья менее 16 см, мышцы выражены слабо, тело вытянуто в продольном направлении. Астеникам “везёт” больше всех 
остальных: их обмен веществ обычно усиленный, они набирают вес не сильно, с возрастом возможно лишь отложение жиров в районе талии. Они обычно имеют проблемы с дефицитом веса. Люди нормостеничной конституции, имеют обычно рост средний или выше среднего, обхват запястья у них составляет в среднем 16-18 см, их тело достаточно гармонично сочетает в себе мышцы и жир, кости скелета достаточно прочные. Обмен веществ у них средний, и, чтобы чувствовать себя комфортно, им необходимо следить за питанием и достаточно двигаться.

Гиперстеники обычно коренастые, невысокие, с широкими плечами, тазом и толстыми прочными костями. Обхват запястья у них более $18 \mathrm{~cm}$. Их вес обычно средний или выше среднего. Их жировой и мышечный корсет наиболее выражены. Чтобы следить за весом, таким людям необходимо наращивать мышечную массу за счёт сжигания жиров.

Если взять средний вес у каждого из типов телосложения, то у нормостеников он будет принят за 100\%, у астеников он на 10\% ниже, а у гиперстеников - на $10 \%$ выше из-за особенностей обмена веществ и строения костно-мышечной системы. У трех женщин одинакового роста, к примеру, в 160 см, и с разными типами конституции идеальный вес соответственно будет:

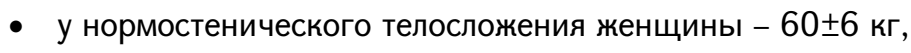

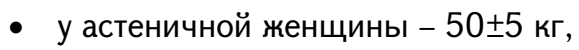

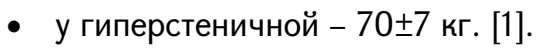

Вес человека (масса тела человека) является относительным показателем физического развития человека и состояния его здоровья. Поэтому установлены определённые весовые нормативы, учитывающие возрастные, половые и другие особенности. Предложено множество методов определения весовых нормативов человека. Поскольку абсолютные величины массы тела зависят в значительной степени от роста человека, то в практической работе в основном применяются некоторые формулы, с помощью которых рассчитывается оптимальный вес человека в зависимости от его роста. Нами были проведены антропометрические измерения (вес и рост) студенток в возрасте $21 \pm 2$ года. Полученные данные рассчитали по орормулам Брока-Брукса, Брейтмана, Лоренца и др. Сравнительный анализ значений нормального веса показал, что наиболее рациональные величины должного веса соответствуют показателям индекса Брока-Брукса.

На сегодняшний день важным параметром оценки веса тела является индекс массы тела (ИМТ, ВМІ), принятый в 1997 году Всемирной организацией здравоохранения (ВО3). Индекс массы тела - это величина, позволяющая оценить степень соответствия массы человека и его роста и, тем самым, косвенно оценить, является ли масса недостаточной, нормальной или избыточной (ожирение). Исходя из индивидуальных параметров организма, рассчитывают оптимальный вес - это именно тот вес, который организму легче всего сохранять и при котором ожидается наибольшая продолжительность жизни. Считается, что оптимальный вес в 
наибольшей степени соответствует среднему весу людей в возрасте 25 лет. Для популяции среднее нормальное значение ИМТ принято равным 22, причём только у взрослых в возрасте от 20 до 65 лет.

\begin{tabular}{|l|l|}
\hline $\begin{array}{l}\text { Диапазон } \\
\text { величин ИМТ }\end{array}$ & \multicolumn{1}{|c|}{ Оценка } \\
\hline Менее 16,0 & 3-я степень хронической энергетической недостаточности \\
\hline $16,0-17,5$ & 2-я степень хронической энергетической недостаточности \\
\hline $17,5-18,5$ & 1-я степень хронической энергетической недостаточности \\
\hline $\begin{array}{l}\text { 18,5-25-0 } \\
(20,0-25,0)\end{array}$ & $\begin{array}{l}\text { Нормальный диапазон, наименьший риск проблем со } \\
\text { 3доровьем }\end{array}$ \\
\hline $25,0-30,0$ & Избыточная масса тела \\
\hline $30,0-35,0$ & 1-я степень ожирения \\
\hline $35-40,0$ & 2-я степень ожирения \\
\hline Более 40,0 & 3-я степень ожирения \\
\hline
\end{tabular}

Таблица 1. Классификация индекса массы тела (ИМТ)

При этом доказано, что величина ИМТ прямо коррелирует с количеством жира в организме, т.е. со степенью ожирения. ИМТ может быть интерпретирован неправильно при наличии отёков или при сильно развитой мускулатуре. Поэтому для окончательного установления диагноза ожирения необходимо привлекать другие методы оценки отложения жира, например, измерение толщины жировых складок, окружности талии и бёдер. [2]

Измерение веса само по себе не даёт точной картины состояния организма, поскольку масса тела человека это сумма веса костей, мышц, внутренних органов, жидкости и жировой ткани. Так, два человека могут иметь одинаковый рост и вес, однако уровень содержания жира у одного из них может быть существенно больше и представлять риск его здоровью.

Количественная характеристика состава тела, оценка всех компонентов являются в конечном итоге отражением баланса энергии и степени удовлетворения потребности организма в энергии. Состав тела имеет существенную взаимосвязь с показателями физической работоспособности человека и его адаптации к среде обитания. Особенно выражена эта взаимосвязь в условиях экстремальной профессиональной и спортивной деятельности. Изучение состава тела является новым, быстро развивающимся направлением биологии человека, его определяют биоимпедансным (реографическим) методом с помощью специальных весованализаторов. Сопротивление различных тканей организма сопоставляется с возрастом, полом и весом, что и в целом определяет показатели состава тела.

Проведённые нами исследования состава тела показали, что разница в весе костей сравнительно мала, в пределах 0.2кг. Разница в весе мышц составила 1-5 кг, 
а разница в весе жира - 0-11кг. Поскольку костная структура не подвержена значительным изменениям в течение короткого периода времени, важно развивать и сохранять здоровье костей путем здоровой сбалансированной диеты и достаточного количества фризических нагрузок.

Отражаемая на дисплее мышечная масса включает скелетные мышцы, гладкие мышцы, а также воду, содержащуюся в этих мышцах. Если мышечная масса возрастает, увеличивается также и потребление энергии, что способствует снижению избыточного жира в организме и потере веса здоровым путём. Уменьшение содержания жира в организме и одновременное увеличение мышечной массы являются наглядным показателем эффрективности программы фризических нагрузок и рациональности снижения веса. Определение количества жира наиболее актуально в спортивной и художественной гимнастике, балете, бодибилдинге, фитнесе, спортивной и клинической медицине. Интересны данные, проведённые в АрмГИФКиС (2000), о динамике перераспределения подкожного жирового слоя у тяжелоатлетов в зависимости от квалификации.

Открытие в 1993 г. гена ожирения и продуцируемого адипоцитами молекулярного фактора лептина положило начало активному изучению жировой ткани как метаболически активного органа. Жир вырабатывает женские гормоны эстрогены. Если количество подкожного жира уменьшается меньше нормы, то эстрогенов начинает не хватать организму, яйцеклетка не может созреть, соответственно может возникнуть аменореа. Обычно "весовой порог менструаций" равен 47-48кг. Вследствие этого у спортсменок может развиться так называемая «триада спортсменок», а именно нарушение менструального цикла, чрезмерное похудания (вплоть до истощения), остеопороз.

Таким образом, определение состава тела повышает эффеективность контроля за состоянием здоровья, за дозированием нагрузки в спорте и фитнесе, работоспособности человека и его качеством жизни.

Однако эндокринологи, а также специалисты по нарушениям метаболизма и ожирению из Пенсильванского университета (США, 2013г.) разработали и предложили на рассмотрение медицинскому сообществу индекс обьема тела (Body Volume Index, BVI), позволяющий более точно прогнозировать риск ожирения для здоровья человека. Он сочетает в себе показатели индекса массы тела (ИМТ) и окружности талии.

$$
\mathrm{ABSI} \equiv \frac{\mathrm{WC}}{\mathrm{BMI}^{2 / 3} \text { height }^{1 / 2}} .
$$

Где: ABSI - индекс формы тела (ИФТ); ВMI - индекс массы тела (ИМТ); WC объем талии (ОТ); height - рост.

Объем талии - это мера для определения количества абдоминального жира у человека. От его наличия и количества во многом зависит общее состояние 
организма человека, в частности уровень холестерина, инсулинорезистентность, артериальное давление. «Если ИМТ говорит о размерах тела, его величине, то ИФТ можно рассматривать как показатель «округлости фрорм», - комментирует один из соавторов исследования NirKrakauer [4]. «Люди с высоким ИФТ имеют «вредную форму тела», хотя могут при этом обладать весом и объемом талии в пределах нормы. Таким людям лучше изменить рацион и образ жизни», - считает ученый. BVI сканер использует 16 датчиков для измерения формы тела, объемных деталей и определяет сотни измерений линейных данных. BVI учитывает вес, рост, форму тела, возраст, пол и историю болезни, чтобы более точно определить степень риска для здоровья от ожирения. BVI способен различать, как вес распределяется в теле, например, в области грудной клетки, живота, таза и бедер.

Таким образом, учение о составе и массе тела, телосложении и физическом развитии постоянно развиваются. Предлагаются новые подходы в подсчёте и интерпретации параметров, используется высокоточное оборудование и инновационные технологии. Наши обследования спортсменов и лиц, занимающихся фритнесом и оздоровительной фризической культурой, будут продолжены в разных направлениях с учётом новейших технологий.

\section{Литература}

1. Карпман В. Л. Спортивная медицина. - М.: Физкультура и спорт, 1987, стр. 42-43.

2. Measuring BMl for adults, children, and teens. By Yvette Brazier. Medical News Today, 2018

3. Michael Dansinger, MD. Weight Loss and Body Mass Index (BMI), WebMD, 2019

4. Krakauer N.Y., Krakauer J.C. A New Body Shape Index Predicts Mortality Hazard Independently of Body Mass Index // PubMed, PLoS ONE - 2012. Vol.7. - P. e39504.

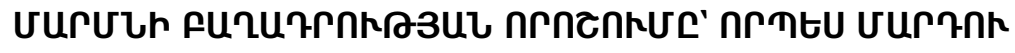

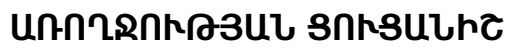

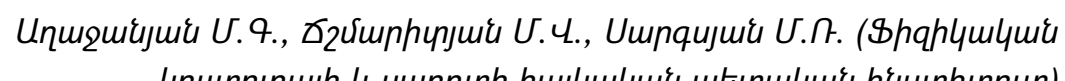

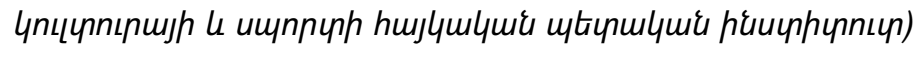

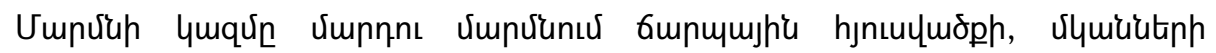

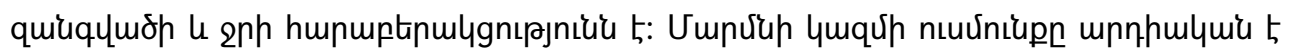

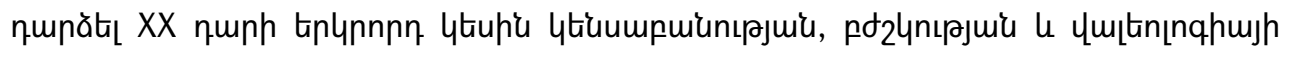

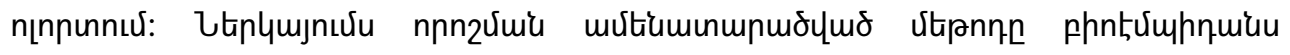

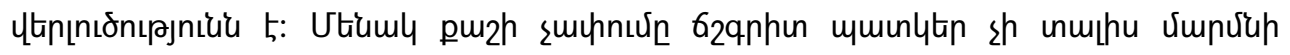




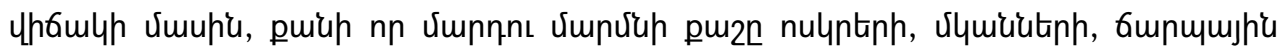

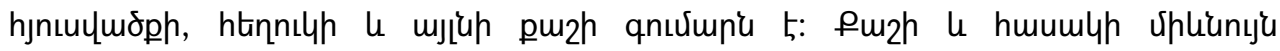

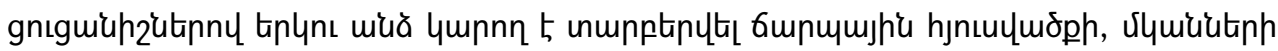

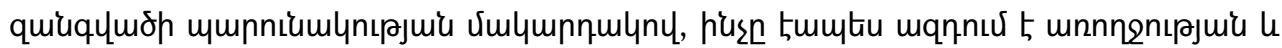

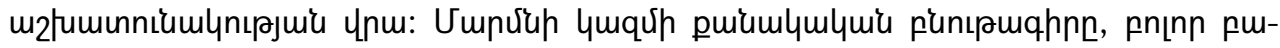

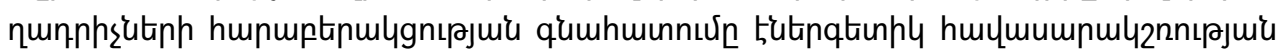

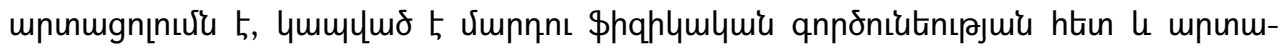

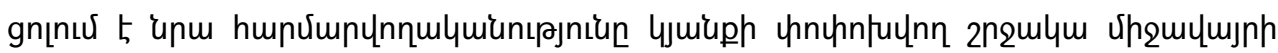

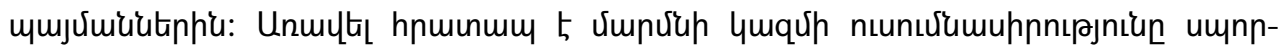

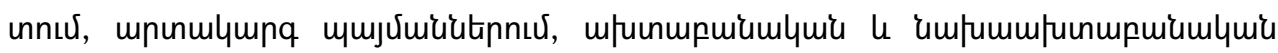
पh6mlyutinnus:

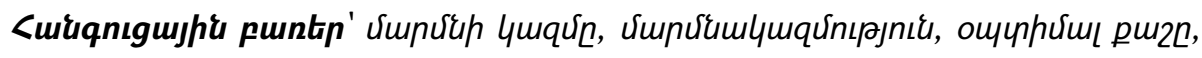

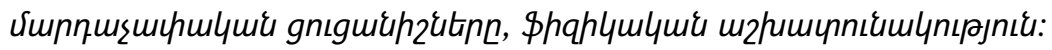

\section{DETERMINATION OF THE BODY COMPOSITION AS AN INDICATOR OF HUMAN HEALTH}

Agajanyan M.G., Chshmarityan M.V., Sarkisyan M.R. (Armenian State Institute of Physical Culture and Sports, Yerevan, Armenia)

The doctrine of body composition has become an urgent area in the field of biology, medicine and valeology in the second half of the 20th century. The most common method of determination at present is bio-impedance analysis. Measuring weight alone does not give an accurate picture of the state of the body, since the body weight of a person is the sum of the weight of bones, muscles, adipose tissue, cerebrospinal fluid, etc. At the same time, two people with the same indicators of weight and height may differ in the level of content of adipose tissue, muscle mass, which significantly affects health and performance. A quantitative characteristic of body composition, an assessment of the ratio of all constituent components is a reflection of the energy balance, correlates with the physical performance of a person and reflects his adaptation to the changing environmental conditions of life. The most urgent problem is the study of body composition in sports, extreme conditions, morbid and premorbid conditions.

Keywords: body composition, body type, optimal weight, anthropometric indicators, physical performance. 